\title{
University Teaching Faculties: A Cross Cultural Study
}

\author{
Seema Munaf, Senior Member, IEDRC
}

\begin{abstract}
This study investigates the cross-cultural perspectives and the effectiveness of overall educational management of Pakistan and Malaysia through performance, achievement motivation and job satisfaction of their teaching faculties. It was hypothesized that "Overall performance, achievement motivation and job satisfaction of Pakistani and Malaysian university teachers would differ". The sample comprised of 120 Chairpersons/heads and their teaching faculties including 60 from Pakistani and 60 from Malaysian Universities. HODs rated teachers on their performance while two senior regular teachers filled achievement motivation and job satisfaction scale. Results indicate that achievement motivation and job satisfaction of Malaysian faculties was significantly more than Pakistani teaching faculties, whereas no significant difference was noted in performance of Malaysian and Pakistani teaching faculties working under their respective heads of educational institution.
\end{abstract}

Index Terms-Achievement motivation, cross culture, job satisfaction, Malaysia, Pakistan, performance, teaching faculties.

\section{INTRODUCTION}

Organizational goals can be achieved through proper management. Management in the educational institutions is not an easy task. In developing Asian countries, Institutions of Higher Education are rapidly developing. Progress of any educational institution depends on variety of factors; however effective management is the significant factor which results in excellent performance, achievement motivation and job satisfaction of teachers. To enhance teachers performance, job satisfaction and achievement motivation and for quality assurance, the proper management of educational institutions is required for which scientific research needs to be conducted.

One aspect of cross cultural comparison through educational management research helps us to understand particular difference in educational management of different cultures is through its effectiveness. Effectiveness of educational management can be understood through, teacher's performance, achievement motivation, and job satisfaction. In Higher education alike other areas of study, proper management is required. If it results in job satisfaction

Manuscript received February 28, 2013; revised April 30, 2013. This work was supported and is only a section of Post Doctoral fellowship study Munaf (2008) funded by AMDISA (SAARC recognized body). Three parts of this study including additional and one main part has already been published in journals (Munaf, 2009, 2011 respectively) and conference proceedings (Munaf, 2010). This is a fourth and main portion as well as extension of Munaf (2009) study.

S. Munaf is with the Institute of Clinical Psychology, University of Karachi, Pakistan (e-mail: drseemamunaf@hotmail.com). and achievement motivation then teacher's performance is expected to increases, which in return results in good grades of the students as well as student's satisfaction with educational environment. Number of researches shows that job satisfaction, achievement motivation and performance are significant factors of well reputed organizations.

Spector (1997) [1] as in Lumley, Coetzee, Tladinyane and Ferreira (2011) [2] consider "job satisfaction" as an attitude of a person about the job and its various factors.

About "Job performance" at job, usually it is believed that it refers to how well a person does his/her work at job situation. Further "Achievement motivation" as cited in Misra and Srivastava (1990, pp. 1) [3], "is a learned disposition to strive to attain success in achievement situation and take pride in accomplishing successful performance".

It is clear from above three descriptions that these variables are related to each others as well as most important for functioning of any organization whether it is financial, educational or entertainment. If proper management is implemented then one can perceive high level institution. Therefore it is important to go through few researches indicative of significance of these three variables.

Lumley et al. [2] communicate that the work of Robbins, (1993) [4], demonstrates a positive and negative relation of attitude towards job and job satisfaction and dissatisfaction respectively. When a person is satisfied with the job then it results in improved work and decreases isolation and opposition behavior which is not conducive for work environment (Morrison 2008) [5].

Manger and Eikeland (1990) [6] analyzed that those educators found dissatisfied with their intrinsic variables are determine to leave the job.

Hence we can say that teacher's job satisfaction is a noteworthy variable that encourages them to execute their work inclusion of teaching, research and administration duties with dedication and devotion so that students can take interest in studies as well as they may become pride of the nation. Once they are motivated to do work appropriately and sincerely, they get internal satisfaction as a result they are able to self motivate to perform well and to reach the organization goals. Syed, Bhatti, Michael, Shaikh and Shah (2012) [7] are of view that personnel contentment helps to make their performance better, and also give way to and less turnovers and absence at work.

Individual's performance, achievement motivation and job satisfaction can be function of particular management style as well as culture in which a person lives. Shaari, Fauziah, and Rosna (2002) [8] found that majority of Malaysian teachers were high on job motivation. Similarly they write that a study on recipients for excellent service, of the institutions of higher learning by Yaakub and Elias (1999) [9] shows that in general their job motivation was moderate and job 
performance was high. Mandal and Dalal (2006) [10] work denote that job satisfaction of the faculty members who were participants of the research was moderate. Munaf (2010) [11] documented that achievement motivation of Pakistani senior teaching faculties was not significantly positively related with transformational and transactional management styles however it was significantly positively related with passive/avoidant management style. It was further demonstrated that their performance was in significantly related with passive/avoidant management style (Munaf, 2011) [12].The research on faculty members of university of Baluchistan, Quetta, Pakistan by Malik (2011) [13] shows that the teachers were generally satisfied with their jobs. On the other hand news report by Richmond (2013) [14] on survey indicates that job satisfaction of teacher of America has reduced.

Working on cross cultural study on university teachers of Pakistan and Malaysia, Munaf (2009) [15] found that the achievement motivation of government and nongovernment Malaysian teachers was better than government and nongovernment Pakistani teachers respectively. Alike, the performance of Malaysian government teachers was better than government Pakistani teachers, although their average score was not in the unsatisfactory category; moreover there was no difference in performance of nongovernment teachers of Pakistan and Malaysia.

Although Pakistan and Malaysia are two Muslim countries yet there is quite difference in their culture. Malaysia is considered as having multicultural society where educational management is pretty difficult as some teachers as well as students belongs to different countries as well as culture. Under this condition it is difficult for the departmental chairpersons as well as teachers to manage the teachers and students respectively. In Pakistan except in few cases, the teachers belong to Pakistan with specific culture. Hence it is expected that overall performance, Job satisfaction and achievement motivation of Pakistani and Malaysian teachers would differ.

Therefore purpose of the present research is to make detail examination of the efficiency of management educational system in general of Pakistan and Malaysia. This would be possible through comparing overall scores of performance, achievement motivation and Job satisfaction of Pakistani and Malaysian teachers. This study is extension of Munaf (2009) [15] study.

\section{A. Hypothesis}

Overall performance, achievement motivation and job satisfaction of Pakistani and Malaysian university teachers would differ.

\section{B. Research Design}

It is a cross cultural comparative study where prevailing university managements would be independent variables and achievement motivation; performance and job satisfaction of Pakistani and Malaysian teachers would be dependent variables.

\section{Methodology}

In this section participant, measures, and procedure of the study would be mentioned.

\section{A. Participants}

Participants comprised of 120 Chairpersons/heads and their teaching faculties including 60 from Pakistani and 60 from Malaysian Universities. Two senior most teachers (Not on leave) having minimum of two years teaching experience in the same department comprised of one teaching faculty. These teachers were nominated by their heads of the departments. The average age of teachers was 37.69 years.

\section{B. Measures}

\section{1) Personal information form (PIF)}

This form gathered information related to personal variables of the participants.

2) University teacher's evaluation rating questionnaire (UTERQ)

Through said Performa performance rating is made of a teaching faculty on ten point rating scale on factors of professional performance, co-professional performance, administrative performance and personality and behavior.

3) Costello achievement motivation scale

(CAMS-adapted english version by Misra \& Srivastava, 1990) [2]

It assesses achievement motivation of a person. It consists of 24 items, which can be answered by making a tick $(\sqrt{ })$ mark under "Yes" or "No" category.

\section{4) Job satisfaction scale (JSS, Singh \& Sharma, 1999)} [16]

It comprised of 30 items which can be rated from $0-4$, as well as from 4-0. The total score indicates job satisfaction/dissatisfaction of a worker.

\section{Procedure}

Proper procedure of taking different consents was followed. Then the Directors/Chairpersons were approached. The entire purpose of the research was explained to them as well as to their two senior regular teachers. After taking their consent first the head were asked to fill Personal Information form and rate two years performance of two nominated teachers on UTERQ. These two teachers were further requested to fill, PIF. In addition, they were requested to complete CAMS, adapted version and JSS. After scoring, t'test was applied in order to compare Pakistani and Malaysian teachers on above mentioned variables. It may be noted that on CAMS and JSS average of two teachers was taken as score of a faculty.

\section{RESUlTS}

In this section the results are entered after data analysis through t'test. First table is given followed by summarization of results in the form of a figure.

Effectiveness of administration in selected educational institutions of Pakistan and Malaysia is significantly different on the variables of ACM and JS of teachers. It is obvious from the mean scores that ACM $(X=16.66)$ and JS $(X=76.46)$ of Malaysian teachers is significantly more, than ACM $(X=14.81)$ and JS $(X=72.28)$ of Pakistani teachers $(t=-4.18$, 
$d f=118, p=.000$ and $t=-2.21, d f=118, p=.02$ respectively)

Insignificant difference was noted on the variable of PER

of Malaysian and Pakistani teachers working under their prevailing educational administrators $(t=-1.12, d f=118$, $p=.26)$.

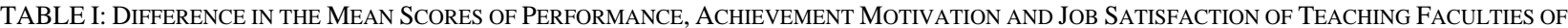
EDUCATIONAL INSTITUTIONS FUNCTIONING UNDER MANAGEMENT OF PAKISTAN AND MALAYSIA

\begin{tabular}{|c|c|c|c|c|c|c|c|}
\hline Variables & $\begin{array}{l}\text { Teaching } \\
\text { Faculties }\end{array}$ & $\mathrm{N}$ & Mean & SD & $\mathrm{t}^{\prime}$ & $\mathrm{df}$ & Sig.(2-tailed) \\
\hline \multirow[t]{2}{*}{ Performance (PER) } & Pakistani & 60 & 57.79 & 17.09 & \multirow[t]{2}{*}{-1.12} & \multirow[t]{2}{*}{118} & \multirow[t]{2}{*}{26} \\
\hline & Malaysian & 60 & 61.05 & 14.69 & & & \\
\hline \multirow{2}{*}{$\begin{array}{c}\text { Achievement } \\
\text { Motivation(ACM) }\end{array}$} & Pakistani & 60 & 14.81 & 2.50 & \multirow[t]{2}{*}{-4.18} & \multirow[t]{2}{*}{118} & \multirow[t]{2}{*}{00} \\
\hline & Malaysian & 60 & 16.66 & 2.33 & & & \\
\hline \multirow[t]{2}{*}{ Job Satisfaction (JS) } & Pakistani & 60 & 72.28 & 11.71 & \multirow[t]{2}{*}{-2.21} & \multirow[t]{2}{*}{118} & \multirow[t]{2}{*}{02} \\
\hline & Malaysian & 60 & 76.46 & 8.75 & & & \\
\hline
\end{tabular}

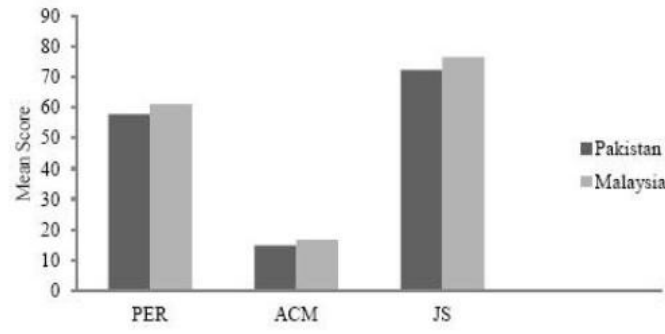

Fig. 1. Difference in the mean scores of the performance (PER) achievement motivation(ACM)and job satisfaction(JS) of teaching faculties of educational institution functioning under management of Pakistan and Malaysia.

\section{DISCUSSION}

The study aimed to determine difference in effectiveness of educational management of selected higher educational institutions of Pakistan and Malaysia. Variables selected to measure management effectiveness were performance, achievement motivation and job satisfaction of teachers. It was hypothesized that, "Overall performance, achievement motivation and job satisfaction of Pakistani and Malaysian university teachers would differ". When overall management of educational institutions of Pakistan and Malaysia was compared, the analysis as shown in the table I, indicates that insignificant variation was noted on the variable of performance between Malaysian and Pakistani teachers whereas significant difference ( but not in negative direction) on the variable of achievement motivation and job satisfaction of teachers was obvious. These were higher for Malaysian faculties. It does indicate that when issue of performance is concern Pakistani teachers try their level best to give their best performance, even though their achievement motivation and Job satisfaction are not similar to teachers of another Asian country.

Our results contradicts conclusion of Ayub (2010) [17], which indicate that job satisfaction results in better performance of teachers. Bowran and Todd (1999) [18] as pointed out by Mandal, and Dalal [10] also propose positive relationship between job satisfaction and job performance. Ayub (2011) [19] further found positive relation between work motivation and job satisfaction. She also noted that Megginson, Mosley and Pietri (1982) [20] are of view that people experiences job satisfaction when they become more expert in their job performance. In the present study however Pakistani teaching faculties are relatively less satisfied with their jobs than Malaysian faculties' still their performance is similar, which shows that, culture difference has not resulted in difference in performance and they are able to perform in like way. This similarity in performance in spite of less job satisfaction and achievement motivation as compared to Malaysians faculties may be due to large sum of investment in education (in the year of data collection) than previous years by Government of Pakistan in order to facilitate teachers to update their knowledge. However, relatively high achievement motivation of Malaysian faculties than Pakistani faculties may be due to globalization of higher education in Malaysia and cultural values initiating the faculty, which facilitate competitiveness and high achievement motivation in teachers(Munaf,2008)[21]. Similar to achievement motivation Malaysian scored also high on job satisfaction. The reason for higher job satisfaction of Malaysian faculties than Pakistani faculties is clear from the writing of Othman, Ghazali and Cheng (2005) [22] which point out that Malay get satisfaction, when they work hard and when their work is completed.

\section{CONCLUSION}

This cross cultural study focusing on comparing effectiveness of management of educational institutions of Pakistan and Malaysia indicate that Job satisfaction and achievement motivation of Pakistan teachers is relatively lower than Malaysian faculties, yet their performance is similar to Malaysian performance which may through light on to the sense of responsibility and dedication to work as well as cultural values of Pakistani teachers.

\section{A. Implications}

This work is of utmost important for Educational Ministry of both the countries to make policies for their educational institutions and their teachers.

\section{B. Limitations of the Study}

Although results of the research are quite clear and noteworthy, however it would have been more appropriate if the data were collected from more than two countries. Scores then would be of utmost importance in making multiple cross-cultural comparisons.

\section{Recommendations}

Education Ministers of Pakistan may set committee to find out reasons for the same and develop policy for improvement 
in job satisfaction and achievement motivation of their university teachers and to bring it to the level of other South East Asian Countries. This may results in improving the status of educational institutions also.

\section{Avenues for Future Research}

- The research may be extended by taking more than two countries for collection of data. It would be more suitable and helpful in understanding educational management of other South East Asian countries too.

- Future comparison of educational management of different levels would give us wider understanding of educational management.

\section{ACKNOWLEDGMENT}

Author acknowledges the support and guidance provided by AMDISA Fellowship Committee in Hyderabad, India and the motivation and institutional support given by the University of Karachi for the Post doctoral fellowship study, as the present paper is one of the portion of it.

Author is also grateful to all the Vice Chancellors, heads and teaching faculties of Pakistani and Malaysian Universities for their cooperation in data collection.

In addition author thanks to editorial team of South Asian Journal of Management (SAJM), for providing consent dated 11-02-2013, for presentation in conference or journal, the remaining part of the study which has not yet published.

\section{REFERENCES}

[1] P. Spector, Job satisfaction: application, assessment, causes and consequences, California: Sage, 1997.

[2] E. J. Lumley, M. Coetzee, R. Tladinyane, and N. Ferreira, "Exploring the job satisfaction and organizational commitment of employees in the information technology environment," Southern African Business Review, vol. 15, no. 1, pp. 100-118, 2011.

[3] O. P. Misra and S. K. Srivastava, Costello Achievement Motivation Scale, adapted, India: Jwalapur: Hardwar: Ambika Pustak Sadan publishers, 1990.

[4] S. Robbins, Organizational Behaviour: Concepts, controversies, and applications, $6^{\text {th }}$ ed., New Jersey: Prentice Hall, 1993.

[5] R. Morrison, "Negative relationships in the workplace: Associations with organizational commitment, cohesion, job satisfaction and intention turnover," Journal of Management and Organization, vol. 14, pp. 330-344, 2008.

[6] Manger and Eikeland, 1990, in A. A. S. G. Syed, N. Bhatti, S. Michael, F. M. Shaikh, and H. Shah, "Job satisfaction of faculty members of universities in Pakistan: A case study of university of Sindh-Jamshoro," Modern Applied Science, vol. 6, no. 7, pp. 89-95, 2012.

[7] A. A. S. G. Syed, N. Bhatti, S. Michael, F. M. Shaikh, and H. Shah, "Job satisfaction of faculty members of universities in Pakistan: A case study of university of Sindh-Jamshoro," Modern Applied Science, vol. 6, no. 7, pp. 89-95, 2012.

[8] A. S. Shaari, Y. N. Fauziah, and A. H. Rosna, "Job motivation and performance of secondary school teachers," Malaysian Management Journal, vol. 6, no. 1-2, pp. 17-24, 2002.

[9] N. F. Yaakub and H. Elias, "Job motivation and job performance: Case of recipients for excellent service in a higher education institution," Malaysian Management Review, June 1999.

[10] G. M. K. Mandal and R. S. Dalal, "Job satisfaction of faculty members of veterinary sciences: an analysis," Livestock Research for Rural Development, vol. 8, no. 7, pp. 89, 2006.

[11] S. Munaf, "Relationship of transformational, transactional and passive/avoidant management style with achievement motivation of teaching faculties of selected educational institutions of Pakistan," in Proc. ICEME, Hong Kong, December, 2010, pp. 93-95.

[12] S. Munaf, "Teacher's quality performance as a function of management style in higher educational institutions," Journal of Alternative Perspective in the Social Sciences, no. 11, pp. 1-17, 2011.
[13] N. Malik, "Study on job satisfaction factors of faculty members at the university of Baluchistan," Journal of Research in Education, vol. 21, no. 2, pp. 49-57. 2011.

[14] E. Richmond. (February 21, 2013). Teacher job satisfaction hits 25-year low. The Atlantic. [Online]. Available: http://www.theatlantic.com.nationalarchive/2013/02/teacher-job-satisf action-hits-25-year-low/273383/

[15] S. Munaf, "Motivation, performance and satisfaction among university teachers: Comparing public and private sectors in Pakistan and Malaysia," South Asian Journal of Management, vol. 16, no. 4, pp. 7-28, 2009.

[16] A. Singh and T. R. Sharma, Job Satisfaction Scale, National PsychologicalCorporation, Agra, India, 1999.

[17] N. Ayub, "A comparative study of private and public universities teachers' job satisfaction," in O. F. V. Feigenblatt, ed., Alternative Perspectives in the Humanities and the Social Sciences, pp. 86-95, 2010.

[18] J. Bowran and K. Todd, "Job stressor and job satisfaction in a major metropolitan public EMS service," Pre hospital and disaster medicine, vol. 14, no. 4, pp. 236-239, 1999

[19] N. Ayub, "The relationship between work motivation and job satisfaction," Pakistan Business Review, pp. 332-347, July 2011.

[20] L. C. Megginson, D. C. Mosley, and P. H. Pietri, Management Concepts and Applications, $4^{\text {th }}$ ed., New York: Harper Collins, 1982.

[21] S. Munaf, "Effectiveness of transformational and transactional management in educational institutions of South/South-East Asia: A cross cultural study of Malaysia and Pakistan," Post Doctoral fellowship research dissertation, AMDISA, 2008.

[22] M. N. Othman, E. Ghazali, and O. C. Cheng, "Demographics and personal characteristics of urban Malaysian entrepreneurs: An ethnic comparison," International Journal of Entrepreneurship and Innovation Management, vol. 5, no. 5-6, pp. 421-440, 2005.

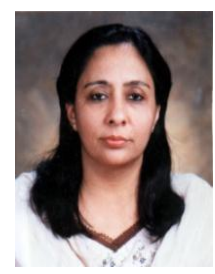

Seema Munaf was born in Karachi, Pakistan on September 30, 1960. She completed her graduation (B.A.) from St. Joseph's college for women in 1981 and masters of arts (M.A., Psychology) from University of Karachi in 1984. She received her post magistral diploma in Clinical Psychology in 1985 and Ph.D. in clinical psychology from the Institute of Clinical Psychology, University of Karachi in 1991. She received Commonwealth AMDISA Postdoctoral fellowship for conducting research related to higher education management, which was completed in 2008

She is affiliated with the Institute of Clinical Psychology, University of Karachi , since 1985, first as a student and intern and then as a research officer, assistant professor, associate professor, assistant to the director (additional charge), professor.

And director (additional charge from May 15, 2001 up to May 23, 2005). At present she is Professor and actively involved in teaching and internship supervision and didactic analysis of Ph.D. clinical psychology students. Various students have completed Ph.D. under her supervision. She has edited a book titled, "Pakistani Woman: Psychological and Social Issues - Selected Research Papers" in 2010 (ISBN-978-969-8883-02-7) and is an author of a book, "Parental Behavior and Psychological Adjustment of School Children", which was published in 2012 (ISBN-978-969-8883-05-8). She has presented various papers and chaired scientific sessions in international conferences. She also conducted innumerable researches, which were published in the journals of International repute. Since 1991 she was on editorial board of Pakistan Journal of Psychology and editor and managing editor from 2001 up to 2005. At present she is on editorial board of various national and International Journals. Her main area of interest in research is in the field of social/ organizational Psychology and educational management. As a Clinician she is expert in the field of Psycho diagnosis, Psychotherapy, Marital/family Counseling, Vocational/Child assessment and guidance.

Prof. Dr. Munaf is also attached to various professional bodies. She is President Sindh and Baluchistan Chapter of Pakistan Association of Clinical Psychologist (PACP), Vice President and Life member of Pakistan Council of Clinical Psychologist (PCCP), Life member of Pakistan Psychological Association (PPA), International affiliate member of American Psychological Association (APA), member Australian Psychological Society (APS), member International Society for Interpersonal Acceptance Rejection (ISIAR),Senior Member of IEDRC, and IACSIT, and Executive Member of Society for the Rehabilitation of the Emotionally Handicapped (SREH). 